\title{
INTERNATIONALIZATION OF BRAZILIAN PSYCHODRAMA
}

\section{INTERNACIONALIZAÇÃO DO PSICODRAMA BRASILEIRO \\ INTERNACIONALIZACIÓN DEL PSICODRAMA BRASILEÑO \\ Heloisa Junqueira Fleury ${ }^{1, *}$}

The Revista Brasileira de Psicodrama is completing 30 years in 2022, an opportunity to celebrate its strengthening as a recognized scientific journal and to evaluate the possibilities of further advances for the next decade.

Many psychodramatists recognized for the excellence of their practices and the teaching of psychodrama avoid the challenge of writing and publishing their articles, making Brazilian psychodrama less known on other continents. This absence of Brazilian articles reflects, in addition to the little familiarity with scientific writing, the difficulty for research and publication in English.

Cultural and linguistic diversity are fundamental, especially in child and adolescent psychiatry, in which the cultural context plays an important role in clinical practice and treatment efficacy (Poremski et al., 2019). In psychodrama, with multiple trends and areas of activity, the cultural diversity brought about by the participation of Brazilian authors will be an important contribution to the development of the approach.

For an update in line with what has been developed abroad, it is essential that Brazilians include recent publications, including in English, in their reviews of the study theme before starting writing. This stage of scientific writing is a requirement for the quality of the article and scientific production in the science world, generating the possibility of being cited in the main international peer-reviewed journals.

Most of those interested in publishing receive limited training for scientific writing. The expectation is that they will learn to write scientific articles by writing, without a formal preparation (Fernandez et al., 2018). These authors evaluated the satisfaction of Spanish undergraduate and graduate students participating in an intense two-day training program for scientific writing and the results confirmed the importance of this discipline.

For authors who do not have English as their primary language, the challenge to publish in international journals is considerable. One example of how this has been addressed is at the Medical University of Tokyo, Japan, which has developed its own platform for submission of its students' manuscripts. All manuscripts go through a process of consulting and editing by highly qualified and experienced teachers. At the same time, the student receives didactic material for training for scientific writing (Barroga \& Mitoma, 2019). Good technological courses facilitate the administration of contributions, but do not replace the dedication of time by students and teachers in the elaboration of the definition of the focus of the article, writing, review after the recommendations of the evaluators and the completion of the manuscript.

A group of American physicians and researchers of Arab origin organized an online course of writing and scientific publication so that colleagues from Syria could report the effects of the war and its adverse conditions from a medical perspective (Sabouni et al., 2017). Initially, 2,588 physicians and medical students joined the group created on social media, 385 completed the initial questionnaire and only 159 completed the program. These results suggest that the topic arouses interest, but that there are impediments to full membership to the task.

Initiatives such as these reported suggest possibilities for action in favor of diversity, equity and inclusion (DEI) of relevant authors in the international scenario. Publishing good articles in English has been increasingly imperative for the development of any area of study, including psychodrama. Reaching the collective of researchers and scholars from all continents ensures the timeliness of scientific knowledge and more opportunities of knowledge exchange among different theoretical tendencies. 
The current movement to leverage DEI in scientific publishing (Fleury, 2021) should include training programs for writing and scientific evaluation. The aim of this editorial is to reflect on the importance of indexing and internationalization of the Revista Brasileira de Psicodrama, as well as to review some practices to improve scientific writing skills.

\section{INDEXING AND INTERNATIONALIZATION}

The evaluation of the quality of a scientific publication is mainly based on indexing and citation criteria. Indexing is the process of including scientific journals in a given database, such as the SciELO Collection. As the most important databases define criteria for this process, participating in one of them tends to be a recognition of quality by the international community.

One of these criteria is based on the impact factor of the journal, related to the frequency with which an article is cited during a given period (Kieling \& Gonçalves, 2007). The visibility of the articles is a necessary condition to increase the number of citations and, consequently, positively influence their impact factor.

Editorial policies, with various regulations, and new proposals of open science in the evaluation process have stimulated the advancement in the quality of research and scientific publication (Gasparyan et al., 2018). As researchers and authors use article search engines in recognized databases for updating, indexing has important implications for the research and development of a study area (Gasparyan \& Kitas, 2021).

The Revista Brasileira de Psicodrama was indexed in the SciELO Collection and the publication will be continuous, allowing articles to reach readers more quickly and be more cited. As indexing opens doors to access to new international databases, facilitating the presentation of published articles to a new audience, this was a decisive step for the internationalization of the different theoretical and practical trends of psychodrama influenced by Brazilian culture.

\section{THE CHALLENGES OF SCIENTIFIC WRITING}

The analysis of instructions to the authors of several scientific journals, from 1987 to 2017, through a systematic review and meta-analysis identified the increasing detailing of items over time, especially in journals with a higher impact factor, in the health area and those more generalists, differences between countries and between databases (Malički et al., 2021). With these criteria of analysis, Malički et al. (2021) suggested professional consulting to meet the growing demands, which was adopted by the Revista Brasileira de Psicodrama in recent years.

However, detailed instructions are not enough for authors. One of the main limitations of the Revista Brasileira de Psicodrama for new and better indexing are the poor familiarity of the psychodramatic community with scientific writing which is one of the possible explanations for the low number of citations of articles in other journals. As in other scientific journals, the training of authors and evaluators for scientific writing is essential.

In relation to the evaluation activity, the Brazilian Association of Scientific Editors (ABEC) offers the distance learning course "Scientific Article Evaluator" with important subsidies for the improvement of evaluations, including guidelines for the implementation of an evaluation process in open science. The differential of this course is learning with practical exercises simulating peer evaluation.

In relation to the authors, most of them have difficulty meeting the specifications for each section of the article, the function of the components of the abstract (introduction, objectives, method, analysis and discussion and final considerations) and in establishing inclusion and exclusion criteria in field research and review articles. Considering the imperative to leverage the DEI principles in the Revista Brasileira de Psicodrama, new references need to be sought to address the limitations of authors with scientific writing.

The general recommendations for scientific writing suggest to start reading important articles previously published on the subject, with an adequate bibliographic review. Even recognizing the intrinsic difficulty of this task, Forero et al. (2020) point out that science advances based on going beyond what is known. This task requires time and discipline, a frequent obstacle among potential authors. 
The International Association for Group Psychotherapy and Group Processes (IAGP) promoted a scientific writing preparation group with participants from various countries. From a series of tips (Grundy, 2021), the sharing of texts and difficulties for scientific writing has stimulated new publications.

The scientific article should be short, compact and simple, avoiding the excessive use of adjectives and adverbs (Forero et al., 2020). The basic topics to improve the scientific writing of authors from other languages are, among others, the correct use of grammar, editorial/scientific style, sentence structure, components of the scientific article, communication in congresses, preparation of the article for publication (Barroga \& Vardaman, 2015).

\section{CONCLUSION}

With the inclusion of the Revista Brasileira de Psicodrama in the SciELO Collection, the editorial committee is in search of new parameters of scientificity to reach higher levels of quality, both in the editorial policy and in the training of those interested in publishing and evaluating the manuscripts submitted to the Revista Brasileira de Psicodrama, to always learn and develop a reflexive and updated learning process.

Theoretical and practical developments of psychodrama, influenced by the rich Brazilian culture, have much to contribute, especially in developing countries. Indexing in the SciELO Collection started this process, with open access to articles, some of them in English.

In this next decade, the training for scientific writing and publication in English becomes imperative for the sharing of cultural diversity, equity among psychodramatists and the increasing inclusion of authors of different theoretical trends and related areas that can contribute to new developments, essential conditions for the internationalization of Brazilian psychodrama.

\section{REFERENCES}

Barroga, E. \& Mitoma, H. (2019). Improving Scientific Writing Skills and Publishing Capacity by Developing University-Based Editing System and Writing Programs. Journal of Korean Medical Science, 34(1), e9. https://doi.org/10.3346/jkms.2019.34.e9

Barroga, E. \& Vardaman, M. (2015). Essential Components of Educational Programs on Biomedical Writing, Editing, and Publishing. Journal of Korean Medical Science, 30(10), 1381-1387. https://doi.org/10.3346/jkms.2015.30.10.1381

Fernández, E., García, A. M., Serés, E. \& Bosch, F. (2018). Students' satisfaction and perceived impact on knowledge, attitudes and skills after a 2-day course in scientific writing: a prospective longitudinal study in Spain. BMJ Open, 8(1), e018657. https:// doi.org/10.1136/bmjopen-2017-018657

Fleury, H. J. (2021). O psicodrama confirma missão política da diversidade, equidade e inclusão. Revista Brasileira de Psicodrama, 29(3), 159-162. https://doi.org/10.15329/2318-0498.00509_PT

Forero, D. A., Lopez-Leon, S. \& Perry, G. (2020). A brief guide to the science and art of writing manuscripts in biomedicine. Journal of Translational Medicine, 18, 425. https://doi.org/10.1186/s12967-020-02596-2

Gasparyan, A. Y., Yessirkepov, M., Voronov, A. A., Koroleva, A. M. \& Kitas, G. D. (2018). Updated Editorial Guidance for Quality and Reliability of Research Output. Journal of Korean Medical Science, 33(35), e247. https://doi.org/10.3346/jkms.2018.33.e247

Gasparyan, A. Y. \& Kitas, G. D. (2021). Editorial Strategy to Get a Scholarly Journal Indexed by Scopus. Mediterranean Journal of Rheumatology, 32(1), 1-2. https://doi.org/10.31138/mjr.32.1.1

Grundy, D. (2021). Tips on professional writing [Unpublished manuscript]. Professional Writing Course, International Association for Group Psychotherapy and Group Processes (IAGP).

Kieling, C. \& Gonçalves, R. R. F. (2007). Assessing the quality of a scientific journal: the case of Revista Brasileira de Psiquiatria. Brazilian Journal of Psychiatry, 29(2), 177-181. https://doi.org/10.1590/S1516-44462007000200017

Malički, M., Jerončić, A., Aalbersberg, I. J., Bouter, L. \& Riet, G. (2021). Systematic review and meta-analyses of studies analysing instructions to authors from 1987 to 2017. Nature Communications, 12, 5840. https://doi.org/10.1038/s41467-021-26027-y

Poremski, D., Falissard, B., Fegert, J., Witt, A., Ordóñez, A. E., Martin, A., Fung, D. S. S. (2019). Moving from ‘personal communication' to 'available online at': preprint servers enhance the timeliness of scientific exchange. Child and Adolescent Psychiatry and Mental Health, 13, 42. https://doi.org/10.1186/s13034-019-0301-4

Sabouni, A., Chaar, A., Bdaiwi, Y., Masrani, A., Abolaban, H., Alahdab, F., ... Al-Moujahed, A. (2017). An online academic writing and publishing skills course: Help Syrians find their voice. Avicenna Journal of Medicine, 7(3), 103-109. https://doi.org/10.4103/ ajm.AJM_204_16 